\title{
Production LHC HTS Power Lead Test Results
}

\author{
M. A. Tartaglia, R. H. Carcagno, S. Feher, Y. Huang, D. F. Orris, Y. Pischalnikov, R. J. Rabehl, C. \\ Sylvester, J. Zbasnik
}

\begin{abstract}
The Fermilab Magnet test facility has built and operated a test stand to characterize the performance of HTS power leads. We report here the results of production tests of $\mathbf{2 0}$ pairs of $7.5 \mathrm{kA}$ HTS power leads manufactured by industry for installation in feed boxes for the LHC Interaction Region quadrupole strings. Included are discussions of the thermal, electrical, and quench characteristics under "standard" and "extreme" operating conditions, and the stability of performance across thermal cycles.
\end{abstract}

Index Terms-Cryogenics, Power Leads, High Tc, Superconducting Magnets

\section{INTRODUCTION}

$\mathrm{T}$ HE US-LHC Accelerator project, by a consortium of US laboratories in collaboration with CERN and KEK, is providing a number of major components for the CERN Large Hadron Collider (LHC). Among them are the final focus quadrupole magnets [1] for four interaction regions, and the cryogenic feed boxes that service them. These feed boxes [2], designed by LBNL and known by the acronym DFBX, will provide all of the cryogenic, power, instrumentation, and vacuum connections to these high gradient quadrupoles. A total of eight feed boxes are being built, and a total of twenty pairs of high current power leads (called DFLX) are needed to conduct current to the Interaction Region quadrupole magnet circuits.

The procurement of HTS power leads by LBNL followed development of a specification [3] for the 7500A HTS current leads and prototype testing at CERN. Twenty pairs of DFLX power leads were built and shipped to the Magnet Test Facility (MTF) at Fermilab, which had previously developed the infrastructure and expertise needed for HTS power lead testing [4]-[6]. After initial inspections, 19 pairs were power tested under conditions similar to the DFBX environment. Two leads could not yet be cryogenically tested due to helium leaks into the insulating vacuum space, and were returned to the manufacturer for repair.

Manuscript received October 5, 2004. This work was supported by the U.S. Department of Energy under contract No. DE-AC02-76CH03000.

M. Tartaglia, R. Carcagno, S. Feher, Y. Huang, D. Orris, Y. Pischalnikov, R. Rabehl, and C. Sylvester are with the Fermi National Accelerator Laboratory, Batavia, IL 60510 USA (phone: 630-840-3890; fax: 630-8402383; e-mail: tartaglia@fnal.gov).

J. Zbasnik is with Lawrence Berkeley National Laboratory, Berkeley, CA 94720 (retired).

\section{DESCRIPTION OF THE HTS CURRENT LEADS}

The Hybrid HTS current leads were produced with a resistive heat exchanger section and an HTS section. The HTS section was constructed from an assembly of $(\mathrm{Pb}, \mathrm{Bi}) 2223$ tapes with a Silver-Gold (4\% by weight) alloy sheath to reduce the thermal conductivity compared to a standard tape used for other applications. The resistive heat exchanger was manufactured from a Phosphorous De-Oxidized Copper material, which had an RRR of 4.5. The room temperature interface, the interconnection between resistive and HTS section and the HTS to LTS intersection was manufactured from Oxygen free high conductivity Copper. The room temperature interface was fitted with a thermostatically controlled heater to ensure the block remains frost-free during periods of excess He gas flow.

The thermal insulation of the lead consisted of a double walled vacuum jacket incorporating a super-insulation material. A NEMA G10 tube and a specifically designed isolator assembly provided electrical insulation between the lead and other local external bodies.

A schematic illustration of the DFLX power lead and instrumentation is shown in Fig. 1. Two Platinum temperature sensors are imbedded in the warm end of the HTS section, and a third Platinum sensor is installed at the warm end of the resistive section. For protection of the lead, redundant voltage taps were specified at each of 7 locations that were chosen to allow measurement of resistance in the bulk conductor sections, as well as across joints between the sections. The measured voltage segments are shown in Figures 1 and 4.

\section{Details of the Test Program}

\section{A. Inspection and Test Preparation}

All power leads received initial warm inspections for mechanical tolerances, instrumentation and electrical properties, and insulating vacuum leak rate measurements were made on each lead and compared with specifications to establish whether the leads could be cryogenically tested. A systematic problem with leaks at the instrumentation connector screw required in-situ repair on every lead (using Loctite ${ }^{\circledR} 7649$ primer and 545 sealant). No further leaks were found in all but two leads, which could not be further tested. Vacuum leak rate measurements were limited by Helium background in MTF, which were typically a few times, but as high as 30 times, the specification level. A small number of 
repairs to resistive temperature detectors (RTD) and Voltage Taps were required; these were made by the manufacturer at MTF prior to these leads being tested. Two leads developed internal shorts from an RTD to the lead, and were returned to the manufacturer for repair following successful cold tests.

Following preliminary checks, pairs of leads were installed

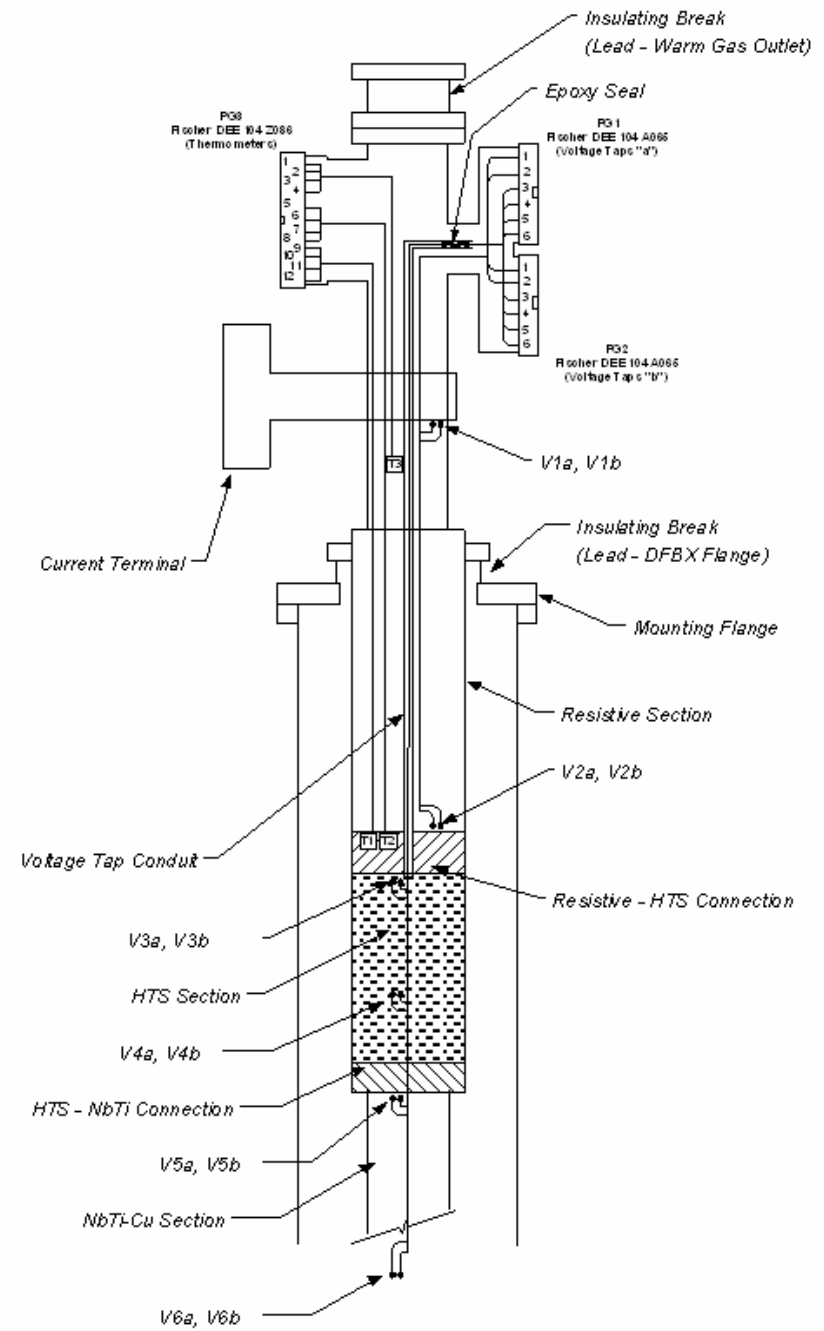

Fig. 1. Instrumentation Schematic of DFLX HTS Power Lead (from [3]).

into the "Chimney" top plate assembly, and tested for their ability to hold pressure. The LTS bus segments were then spliced together by a clamping fixture. The assembly was inserted into the helium test dewar for system electrical checks, and tested for high voltage standoff ("hi-pot" to 1500 V) in warm helium. During cool down to liquid helium temperature, resistances of the voltage tap segments were monitored, and at $4.5 \mathrm{~K}$ a second, identical, cold hi-pot test was done; all pairs easily passed the warm and cold (all $<10$ $\mu \mathrm{A}$, typically $<1 \mu \mathrm{A})$ leakage current requirements $(<50 \mu \mathrm{A})$.

\section{B. Cryogenic Power Test Program}

The test stand design and commissioning details are described elsewhere [7]. After passing cold hi-pot tests, the power lead flags were connected to the positive and negative terminals of the $10 \mathrm{kA}$ power system using water-cooled flexible cables; this presented a low inductance resistive short circuit to the power system [8] (which required some exploration to find suitable operating parameters for low ripple current regulation). Software quench detection thresholds were set to $1 \mathrm{mV}$ for HTS and joint segments, and $100 \mathrm{mV}$ for resistive segments.

\section{CRyogenic ANd Power Test Program}

In the standard test plan, nominal operating conditions were established using PID controls to set the Helium gas inlet temperature ( $20 \mathrm{~K}$ ) and HTS warm end temperature (45-50 K) and determine the gas flows to maintain stable conditions (for 30 minutes) at zero current ("standby" mode). All ramps were performed at $200 \mathrm{~A} / \mathrm{s}$ to plateau, followed by a stabilization period to see if any run-away instabilities (e.g., thermal or quench) occurred following the transient.

First, a set of stair-step ramps was executed to measure joint resistances versus current. Coolant loss tests were then performed separately on each lead: the source of $20 \mathrm{~K}$ Helium gas to the lead was turned off while powering at $7500 \mathrm{~A}$, to see if the proper behavior was obtained. In particular, both HTS and resistive section voltages rise after loss of cooling flow, one of which reaches the quench detection threshold and causes a slow power supply ramp down; the HTS section should not quench under these conditions. A typical example is illustrated in Fig. 2 and Fig. 3, which show helium flow, temperature, current, and voltage trends during a test. Following the coolant loss test, the lead was powered at 7500 A to test performance and stability (for 60 minutes) and determine cooling flows for nominal conditions (20 K Helium gas inlet, 45-50 K HTS warm end temperatures).

Initially during the production test program, lead pairs were power tested again after at least one $300 \mathrm{~K}$ warm up, $4.5 \mathrm{~K}$ cool down thermal cycle. No performance changes were observed in many tests, so the final six pairs were tested with a single cool down only.

\section{Cold Test Results}

The production test program was completed within the predicted time frame. All of the leads tested have successfully met the specified requirements for stable operation at LHC.

The cooling flows needed to establish nominal operating conditions in "standby" mode were about half the specified $0.3 \mathrm{~g} / \mathrm{s}$ upper limit. At $7500 \mathrm{~A}$ however, a majority of the leads required flows above the specified limit of $0.45 \mathrm{~g} / \mathrm{s}$. A histogram of the required flows, measured at $45 \mathrm{~K}$ and $50 \mathrm{~K}$, is shown in Fig. 4. However, an important related criterion that there be no frost or condensation was met for all leads, even with the slightly elevated cooling flows.

All 38 leads passed the coolant loss test. No evidence of any performance change (e.g., in joint and section resistances) was detected following this test, or after thermal cycling the first 26 leads.

Pressure drops in the cooling circuit, from the $20 \mathrm{~K}$ inlet to $300 \mathrm{~K}$ outlet, were all well below the specification of $<50$ mbar: values ranged from 1 to $10 \mathrm{mbar}$, and $<5$ mbar was 
typical.

All but 2 of the leads met the requirement for HTS-LTS joint resistance to be less than $5 \mathrm{n} \Omega$; individual measurement errors were typically $1 \mathrm{n} \Omega$, and these two were within 1.5 standard deviations of the specification. The sample of 38 leads had a mean joint resistance of $3.4 \mathrm{n} \Omega$, with standard deviation $1.0 \mathrm{n} \Omega$; the data are histogrammed in Fig. 5.

None of the leads developed any instability or quenches by ramping at $200 \mathrm{~A} / \mathrm{s}$, well above the specified $100 \mathrm{~A} / \mathrm{s}$ ramp rate.
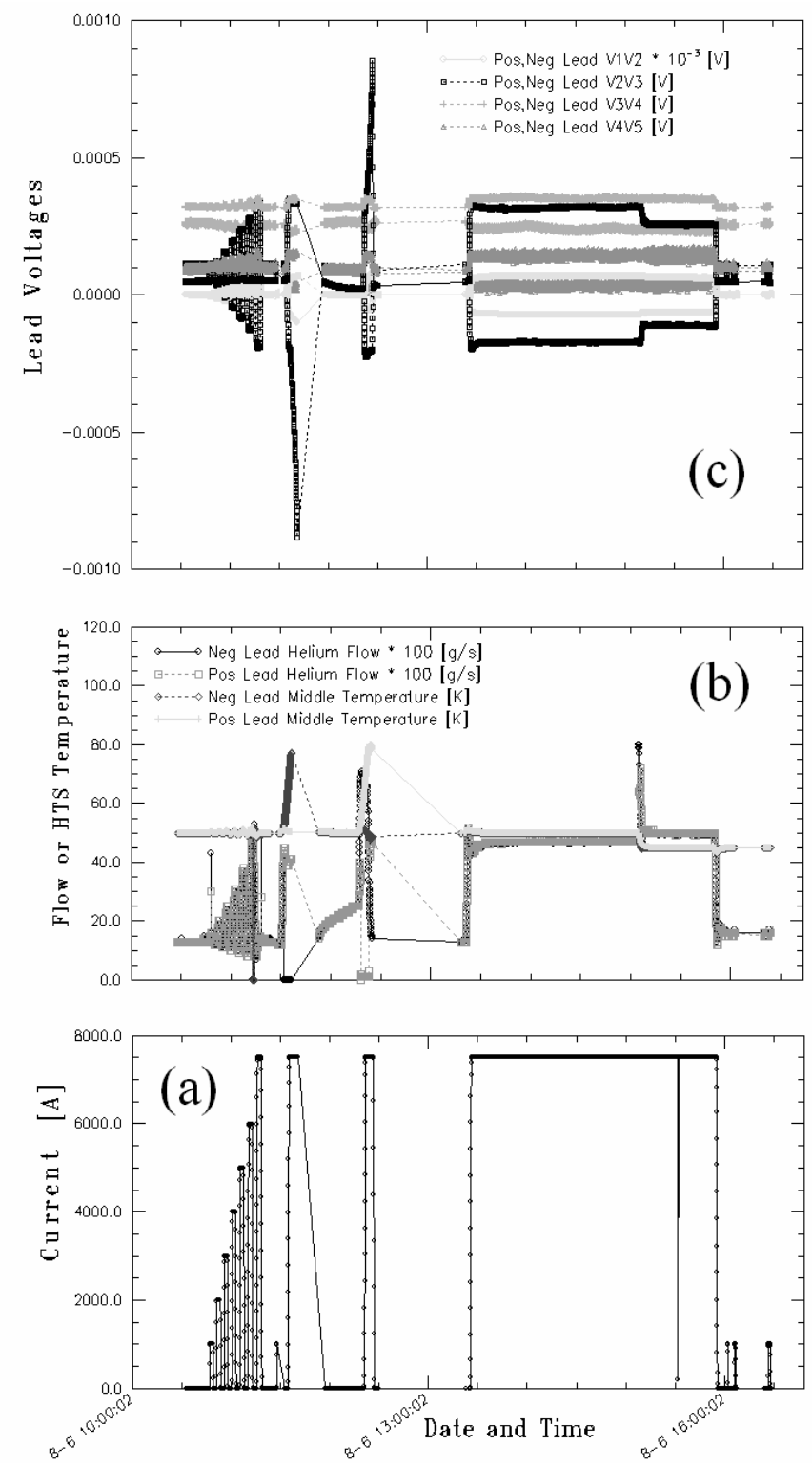

Fig. 2. DFLX26, DFLX25 Thermal Cycle 2 test history, a) Current b) Flow and Temperature, c) Positive and Negative Lead Voltages versus time during the cryogenic power test.

\section{CONCLUSION}

The production tests of 38 HTS power leads, manufactured in industry to US-LHC specifications, have been completed at the Fermilab Magnet Test Facility, over the period from stand commissioning in January, 2003 until May, 2004. By most measures, the leads meet or exceed the specifications. The exception is that slightly greater coolant flow, by up to $20 \%$, is required in the normal powered operating state for a majority of the leads; however, this should not be a problem since frost and condensation at the top were not observed in any test. The leads performed well under "extreme" conditions such as coolant loss tests, high ramp rate, and thermal cycling, after which they showed no evidence of performance changes. Although one pair is yet to be power tested, we conclude the test program and lead performance have both been successful.

\section{ACKNOWLEDGMENT}

This project was made possible by the dedicated assistance of many talented people in the Fermilab Magnet Test Facility and Technical Division, whose help is greatly appreciated.

\section{REFERENCES}

[1] S. Feher, et al., "Test Results of LHC Interaction Region Quadrupoles Produced by Fermilab," submitted for publication to this conference.

[2] R. Byrns, et al., "The Cryogenics of the LHC Interaction Region Final Focus Superconducting Magnets,” LHC Project Report 219, ICEC '17 Conference 14-17 July, 1998, Boumemouth, UK.

[3] J. Zbasnik, “7.5 kA HTS Current Lead Specification:”, LBNL Specification Serial \# M923B, 6 August, 2001.

[4] J. Nogiec, S. Feher, D. F. Orris, J. Sim, M. Tartaglia, "Architecture of HTS Leads Software Protection System," Proceedings of the 1999 Particle Accelerator Conference, New York, p1426-1428,.

[5] G. Citver, et al., "HTS Power Lead Test Results", Proceedings of the 1999 Particle Accelerator Conference, New York, October 1999

[6] G. Citver, et al., "Thermal Tests of 6kA HTS Current Leads for the Tevatron”, Proceedings of the Cryogenic Engineering Conference, Montreal, Canada, November 1999.

[7] R. J. Rabehl, et al., " New Facility for Testing LHC HTS Power Leads," FERMILAB-CONF-04-237-TD, October, 2004.

[8] R. Carcagno, et. Al, "Ripple Current Effects on the performance of superconducting high field magnets using a new $30 \mathrm{kA}$ Power System at Fermilab”, submitted for publication to this conference. 

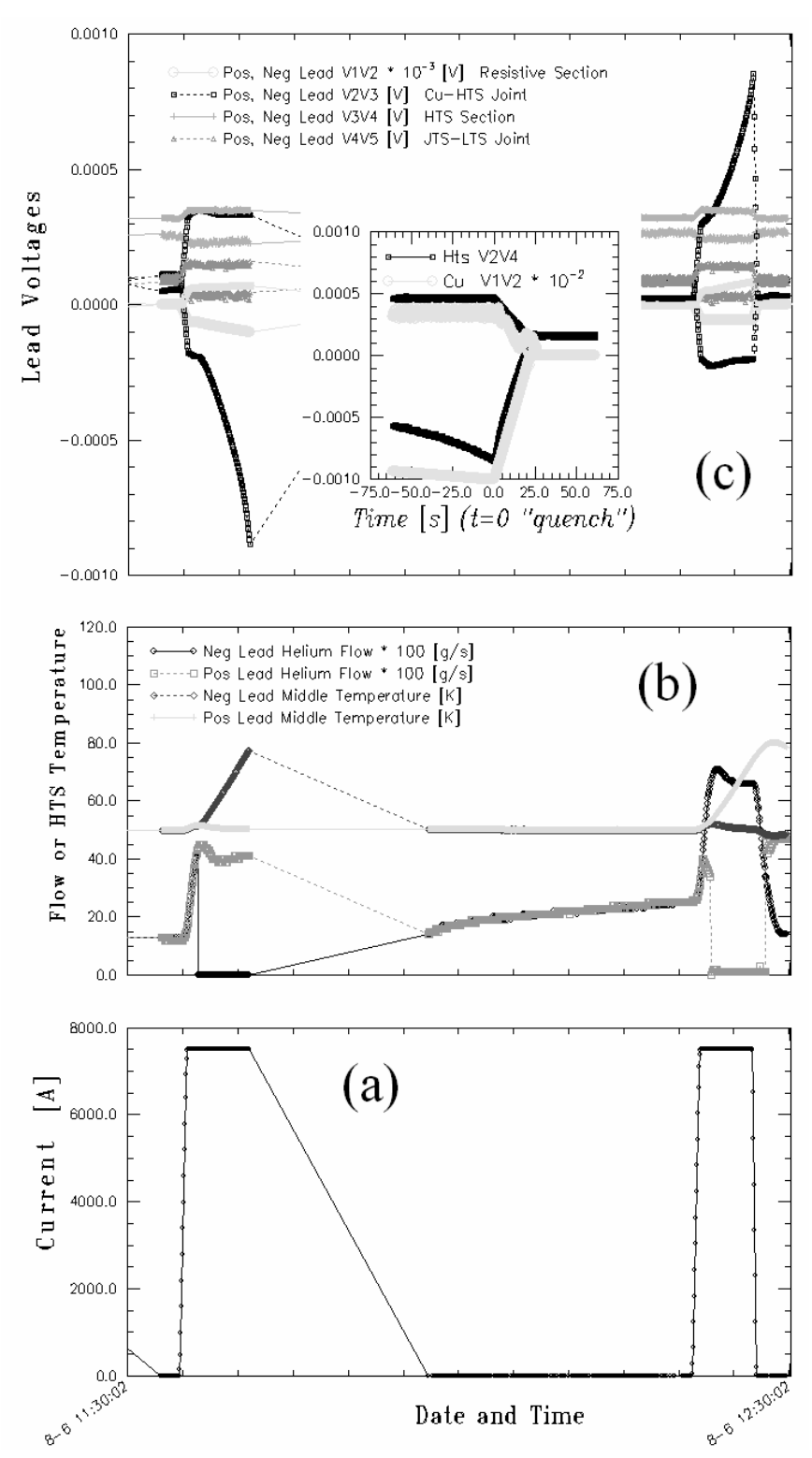

Fig. 3. Details of the coolant loss test, (a) Current (b) Flow and Temperature, (c) Positive and Negative Lead Voltages; Insert in (c) shows "quench" data captured when Copper section voltage reached the $100 \mathrm{mV}$ threshold, and voltages recover after the current drops.

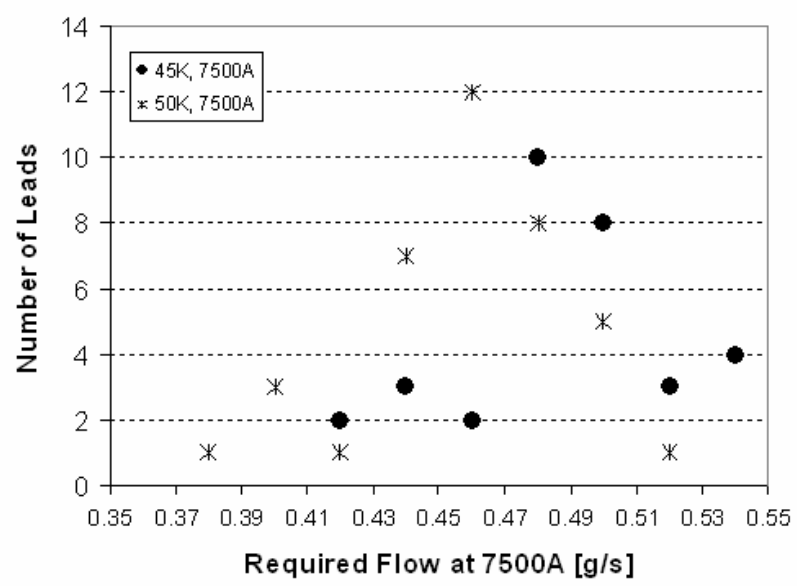

Fig. 4. Histogram of cooling flow required to establish nominal conditions at $7500 \mathrm{~A}$, for Twarm $=45 \mathrm{~K}$ (solid) and $50 \mathrm{~K}$ (dashed)

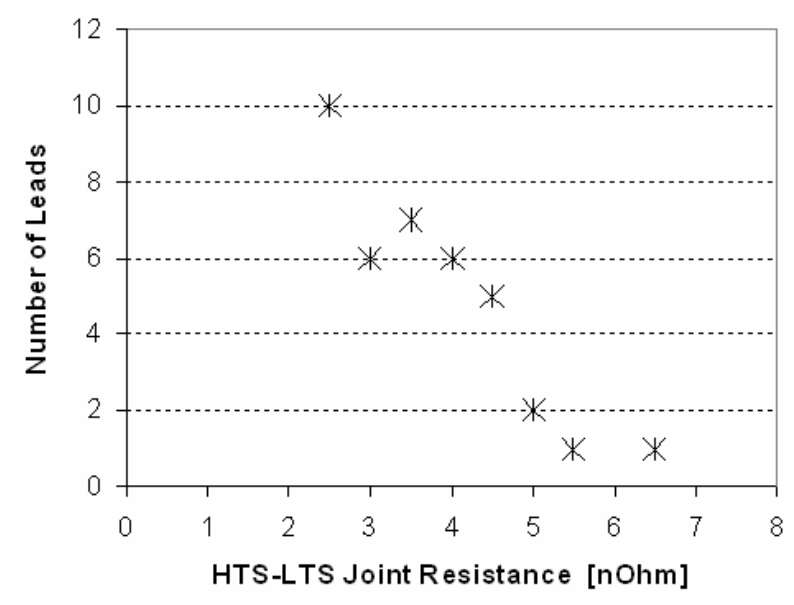

Fig. 5. Histogram of HTS-LTS Splice Resistance Values 